\title{
Uso de Índices de Localização para Identificar Indicações Geográficas na Região Metropolitana de Brasília
}

\author{
Using Locational Index to Evaluate Brasília Metroplitan Region \\ Geographical Indications
}

\author{
Alessandro Aveni ${ }^{1}$ \\ ${ }^{1}$ Universidade de Brasília, Campus Darcy Ribeiro, Brasília, DF, Brasil
}

\begin{abstract}
Resumo
Este artigo discute o uso da metodologia proposta pelo autor no curso de mestrado PROFNIT do NIT de Brasília sobre a utilização de análises quantitativas (indicadores locacionais - QL) e APLs para identificar Indicações Geográficas na Região Metropolitana de Brasília. Com o uso de dados quantitativos de APL e do Censo Agropecuário do IBGE, é possível identificar a concentração de produção para produtos locais com alto potencial para se tornarem certificados. A pesquisa exploratória mostra que a produção de mel e de morango tem uma concentração na Região Metropolitana de Brasília que poderia ser explorada com pedido de Indicação Geográfica pelas associações de produtores. Confirma-se, assim, a metodologia usada e a proposta de aumentar as análises no Distrito Federal.
\end{abstract}

Palavras-chave: Indicação Geográfica. APL. Região Metropolitana de Brasília. Quociente Locacional.

\begin{abstract}
The paper shows the use of the author's proposed methodology by the NIT Brasilia PROFNIT Masters Course, on the use of quantitative analysis (location indicators - QL) and APL to identify Geographical Indications in the Brasilia Metropolitan Region. Using quantitative APL data and the IBGE agricultural census, it is possible to identify a production concentration for local products with high potential to become certified. Exploratory research shows that the production of honey and strawberry has a concentration in the metropolitan region of Brasilia that could be explored at the request of geographical indications by producer associations. This confirms the methodology used and the proposal to increase DF exploration analyses.
\end{abstract}

Keywords: Geographical Indication. APL. Brasilia Metropolitan Region. Locational Quotient.

Área Tecnológica: Propriedade Intelectual. Métodos Estatísticos para Avaliar IG.

\section{Introdução}

Brasília se encontra em uma Região Metropolitana de grande potencial comercial, essa região articula produções agrícolas típicas do Estado de Goiás e possui um dos maiores centros de consumo do país. No Centro-Oeste estão presentes somente quatro Indicações Geográficas (IGs) das 68 totais presentes no Brasil (sendo oito estrangeiras). Somente duas pertencem ao 
Estado de Goiás e estão localizadas em Pirenópolis e na Região de Mara Rosa. Não há IG na Região Metropolitana de Brasília.

Por que não há ainda uma IG no DF? Quais informações podem ser usadas para pesquisar possíveis IGs na Região Metropolitana? Essas são perguntas que ainda não têm respostas e justificam uma pesquisa exploratória, sobretudo, quantitativa.

O objetivo deste trabalho é explorar as informações quantitativas disponíveis com o uso de índices de localização para definir quais produtos agrícolas podem ser interessantes para uma certificação de IG na Região Metropolitana de Brasília. O ponto de partida desta pesquisa são os arranjos produtivos de atividades agrícolas e os produtores concentrados no território metropolitano, como será explicado na metodologia.

Este artigo é parte de uma pesquisa pós-doutoral que trata sobre o referencial teórico de pesquisa e metodologia. $\mathrm{O}$ atual trabalho mostra o desenvolvimento inicial da pesquisa, os resultados obtidos e se justifica, pois, no DF, não existem trabalhos sobre o tema.

\section{Referencial Teórico Sobre IG}

A Indicação Geográfica (IG) tem como base legal internacional e sua definição encontra-se no artigo 22 do Agreement on Trade-Related Aspects of Intellectual Property Rights (TRIPS) que foi incorporado na legislação brasileira coma seguinte tradução.

Indicações Geográficas são, para os efeitos deste Acordo, indicações que identifiquem um produto como originário do território de um Membro, ou região ou localidade deste território, quando determinada qualidade, reputação ou outra característica do produto seja essencialmente atribuída à sua origem geográfica (BRASIL, 1994, p. 7)

As indicações geográficas identificam bens como originários do território de um Estado-Membro, uma região ou localidade nesse território, em que uma qualidade, reputação ou outra característica do bem é essencialmente atribuível à sua indicação geográfica. A OECD (2000) relaciona a IG às mercadorias originárias de um determinado país, região ou localidade, sendo a certificação IG um reconhecimento nesse país como um sinal indicando que os bens: (a) são originários desse país; e (b) têm qualidade, reputação ou outras características atribuíveis à sua origem geográfica.

No Brasil, a Lei n. 9.279/1996 (Lei da Propriedade Industrial - LPI) reconhece e regulamenta a IG em seus artigos 176 a 182. A lei está harmonizada com o documento do Agreement on Trade-Related Aspects of Intellectual Property Rights (BRASIL, 1994) sobre propriedade intelectual e é obrigatória para todos os Países-Membros da Organização Mundial do Comércio (OMC ou WTO). Os requisitos para registro das IGs foram estabelecidos pelo Ato Normativo n. 134/1997 do Instituto Nacional da Propriedade Industrial (INPI), que identifica os formulários para apresentação de requerimento de registro de IGs, e pela Resolução n. 75/2000 do INPI, que apresenta as condições para o registro das IGs, além de serem atualizados pela Instrução Normativa n. 25/2013 
A IG se desdobra seguindo a legislação brasileira em duas certificações:

a) Indicação de Procedência (IP): é o nome geográfico de um país, cidade, região ou uma localidade de seu território que se tornou conhecido como centro de produção, fabricação ou extração de determinado produto ou prestação de serviço.

b) Denominação de origem (DO): é o nome geográfico de país, cidade, região ou localidade de seu território que designe produto ou serviço cujas qualidades ou características se devam exclusiva ou essencialmente ao meio geográfico, incluídos fatores naturais e humanos.

A IG qualifica e valoriza os lugares e os grupos sociais residentes. Na região produtora, a certificação IGs promove os produtos e sua herança histórico-cultural, que é intransferível. A herança abrange vários aspectos relevantes: área de produção definida, tipicidade, autenticidade com a qual os produtos são desenvolvidos e a disciplina quanto ao método de produção, garantindo um padrão de qualidade. As IGs podem ajudar também na preservação da biodiversidade, do conhecimento e dos recursos naturais e trazem contribuições extremamente positivas para as economias locais e para o dinamismo regional, pois proporcionam o real significado da criação de valor local. Ao mesmo tempo em que há uma qualidade diferenciada, ela está protegida por esse reconhecimento ser unicamente dos produtores daquela região.

Os Arranjos Produtivos Locais (APLs) são entidades incluídas nos Planos Plurianuais desde 2000, no Plano Nacional de Ciência Tecnologia e Inovação, 2007-2010, e na Política de Desenvolvimento Produtivo, 2008-2013, entre outros. O Grupo de Trabalho Permanente para APLs (GTP APL), coordenado pelo Ministério do Desenvolvimento, Indústria e Comércio Exterior (MDIC), é integrado por 33 instituições públicas e privadas. Foram estimulados Núcleos Estaduais de Apoio aos APLs em cada uma das Unidades da Federação, além de iniciativas privadas de organismos de representação empresarial e de agências internacionais.

O conceito de APL nasce a partir de conceitos definidos pelo economista Alfred Marshall em seu livro Principles of Economics, cuja primeira edição foi publicada em 1890 e a oitava e definitiva, em 1920. Marshall descreve a maneira como surgem aglomerações setorialmente especializadas. De acordo com o autor, uma aglomeração setorial de empresas origina-se da existência de determinados recursos naturais numa região, de melhores condições de logística ou de um processo histórico que instale determinada atividade produtiva no território (MARSHALL, 1920 p. 232-233).

Existe uma vasta literatura internacional desde o século passado, e, recentemente, também no Brasil, sobre o fenômeno da aglomeração de empreendimentos de uma mesma atividade produtiva em uma determinada região geográfica. Há muitas denominações e ênfases diferentes. O mesmo fenômeno é, às vezes, denominado como arranjo produtivo local, sistema produtivo local ou mesmo cluster. Na concepção brasileira, um APL é formado por um conjunto de atores econômicos, políticos e sociais, localizados em uma mesma região, desenvolvendo atividades produtivas especializadas em um determinado setor e que apresentam vínculos expressivos de produção, interação, cooperação e aprendizagem (SISTEMA FIESP, 2014). Em 2014, o Grupo de Trabalho de APL definiu os Arranjos Produtivos Locais no Brasil como: 
[...] aglomerações de empresas, localizadas em um mesmo território, que apresentam especialização produtiva e mantêm vínculos de articulação, interação, cooperação $e$ aprendizagem entre si e com outros atores locais, tais como: governo, associações empresariais, instituições de crédito, ensino e pesquisa. (SISTEMA FIESP, 2014, p. 9)

Segundo o Grupo de Trabalho Permanente de Arranjos Produtivos Locais (GTP APL), que representa a visão do Governo Federal sobre arranjos e que vem desenvolvendo um trabalho com alguns APLs pilotos nas Unidades da Federação, um APL deve ter as seguintes características:

a) um número significativo de empresas no território e de indivíduos que atuam em torno de uma atividade produtiva predominante; $e$

b) compartilhar formas percebidas de cooperação e algum mecanismo de governança.

A relação APL com IG é simples, pois o APL identifica o potencial produtivo e a concentração do mercado relacionado a produtos e serviços. Alguns APLs têm base na atividade agropecuária, o que leva a concluir que existem produtores e associações de produção interessados em ações coletivas de pedidos de Marcas e IG. As IGs podem certificar e apoiar o marketing dos produtores incluídos nos APLs, ampliando a visibilidade nacional e internacional dos produtos e aumentando, ao final, o valor adicionado da oferta. Assim se cria um círculo virtuoso que pode expandir o interesse em produzir no mercado tanto quanto a demanda de produção de qualidade.

A IG se relaciona com os APLs ainda, pois as associações interessadas na IG são aglomerações como os APLs que buscam um preço premium (ou mais alto valor adicionado ao produto) que se justifica com os lugares e as cadeias produtivas. Esse preço é estritamente ligado à certificação da qualidade de um produto reconhecida e relacionada à busca, à experiência $e$ à credibilidade. Enquanto a qualidade de um produto industrial é sempre questionada, porque não está certificada e ligada a uma produção regional e local conhecida no tempo, no caso da indicação geográfica, acontece o contrário.

Conforme apontam Cassiolato e Arroio (2005), as principais peculiaridades de um APL são:

a) a dimensão territorial (os atores do APL estão localizados em certa área onde ocorre interação);

b) a diversidade das atividades e dos atores (empresários, sindicatos, governo, instituições de ensino, instituições de pesquisa e desenvolvimento, ONGs, instituições financeiras e de apoio);

c) o conhecimento tácito (conhecimento adquirido e repassado por meio da interação, conhecimento não codificado);

d) as inovações e os aprendizados interativos (inovações e aprendizados que surgem com base na interação dos atores); $e$

e) a governança (liderança do APL, geralmente exercida por empresários ou pelo seu conjunto representativo - sindicatos, associações).

A pesquisa sobre IG não pode ser separada da análise dos APLs em cada Estado, pois, se não houver APL reconhecido pelas instituições de governo, o arranjo não vai ter o papel de prioridade local. Também não apresenta produtos ou serviços de volume bastante interessante 
para ter apoio político para desenvolvimento local. Com isso, é possível que uma associação qualquer possa obter o certificado de IG, mas certamente os produtos têm, na visão do desenvolvimento público do território, uma prioridade menor a respeito dos APLs. Em outras palavras, os APLs devem ter um interesse privado e público.

Outro elemento que mostra a necessidade de usar APL para análise é que, para obter dados e documentação de pedido de certificação de IG, fica mais fácil trabalhar com APL. O Banco do Brasil e O BNDS são mais orientados em trabalhar com APL no âmbito dos governos Federal e Estadual, sendo entidades que já tiveram fomento e suporte em muitos lugares ao longo dos anos, com fins de desenvolvimento econômico local. Esse é outro elemento que mostra a utilidade de usar os APLs para análises. Apoiar a pesquisa de arranjos produtivos no território usando APLs garante articulação e continuidade das Políticas Públicas.

\section{Metodologia}

Na primeira fase da pesquisa foram levantados os APLs presentes na Região Metropolitana de Brasília. As informações foram analisadas para encontrar dados quantitativos. Depois dessa triagem foram levantadas informações quantitativas presentes no IBGE relativas ao último censo agrícola.

Uma vez obtidos dados quantitativos, existem diversas metodologias (por exemplo, as de Britto e Albuquerque (2001, 2002), Sebrae (2003), Suzigan et al. (2003) e de Crocco et al. (2003) para identificar APLs e produções que podem ser interessantes para o pedido de IG. De acordo com Crocco et al. (2003), para a elaboração de critérios de identificação de arranjos produtivos locais, é interessante elaborar um indicador que seja capaz de captar quatro características de um APL: (1) a especificidade de um setor dentro de uma região; (2) o seu peso em relação à estrutura industrial da região; (3) a importância do setor nacionalmente; e (4) a escala absoluta da estrutura industrial local.

$\mathrm{Na}$ análise de Crocco et al. (2003) e na literatura nacional, existem trabalhos que propõem metodologias de identificação de arranjos produtivos locais, a saber: Brito e Albuquerque (2002), SEBRAE (2003). Uma medida estatística usada nos três trabalhos e adequada para a análise é o Quociente Locacional (QL) da indústria.

$$
Q L=\frac{E_{j}^{j} / E_{j}}{E_{B R}^{i} / E_{B R}}
$$

$=$ Emprego do setor $i$ na região $j ; E_{j}^{i}$

$=$ Emprego total na região $j ; \mathrm{E}_{\mathrm{j}}$

$=$ Emprego do setor $i$ no Brasil; $\mathrm{E}_{\mathrm{BR}}^{\mathrm{i}}$

$=$ Emprego Industrial Total no Brasil

$\mathrm{Na}$ atual pesquisa, os cálculos dos índices de localização foram desenvolvidos somente por algum APL, como mostrado sucessivamente, e, partindo desses índices, foram calculados os indicadores. Essa limitação aconteceu porque não foi possível avaliar toda a Região Me- 
tropolitana devido à falta de informações quantitativas confiáveis. Além disso, nem todos os APLs são relativos a produtos agrícolas. A pesquisa foi se ajustando a um recorte que não era possível definir inicialmente, mas aconteceu durante o tratamento das informações. Em outras palavras, as tentativas e os erros eram esperadas, já que, sendo uma pesquisa exploratória, as implicações se tornaram claras somente depois da análise dos dados.

\section{Resultados da Pesquisa Exploratória}

Com base na pesquisa, considerou-se que a Região Metropolitana de Brasília tem relação muito próxima com os APLs de Goiás. Em Goiás há, segundo pesquisa do IPEA (2017), cerca de 60 APLs reconhecidos.

A seguir apresenta-se um mapa do Estado de Goiás que mostra os APLs da agroindústria do estado, em particular, as APLs de apicultura, de fruticultura e de minhocultura.

Figura 1 - APLs de Goiás do agronegócio

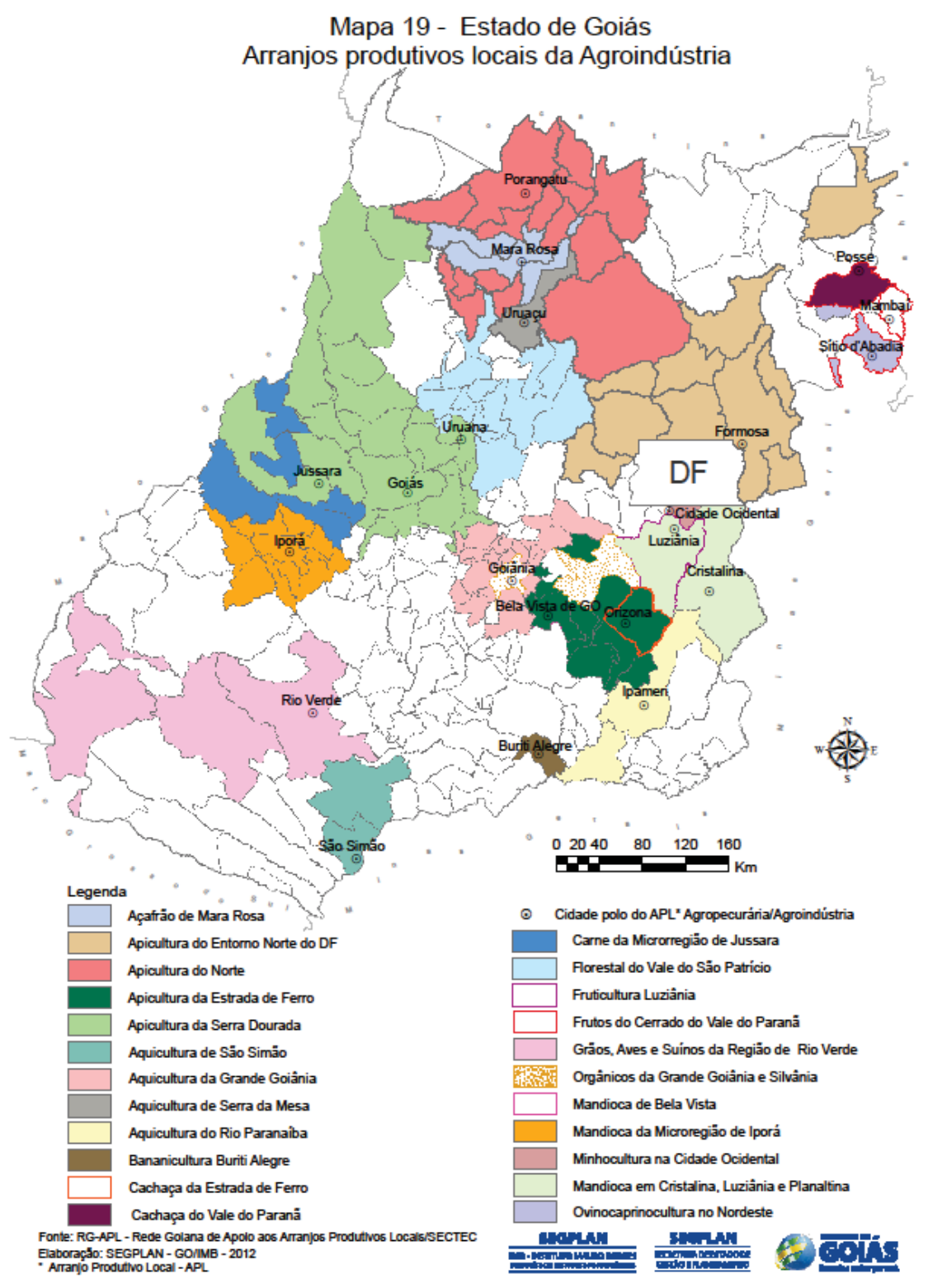

Fonte: Goiás (2020) 
Segundo dados coletados no pela UFRJ (2015), são considerados APLs da Região Integrada de Desenvolvimento do Distrito Federal e Entorno (RIDE-DF), que aproximadamente é a Região Metropolitana de Brasília ${ }^{1}$, estes:

a) Cristalina: APL de Artesanato Mineral - Convenente Executor IEL/SENAI/DR-GO.

b) Luziânia: APL de Fruticultura - Convenente Executor IEL/SENAI/DR-GO.

c) Pirenópolis: APL de Quartzito - Convenente Executor IEL/SENAI DR/GO.

d) Novo Gama: APL de Confecção de Vestuário - Convenente Executor: SENAI DR/GO.

e) Valparaíso: APL Moveleiro de Valparaíso - Convenente Executor: EL/SENAI DR/GO.

f) Águas Lindas: APL de Confecção - Parceiros: Secretaria de Indústria e Comércio de Goiás: IEL/SENAI/GO.

g) Cidade Ocidental: APL de Minhocultura - Parceiros: Prefeitura e ONGs.

h) Buritis/MG: APL de Desenvolvimento da Pecuária Leiteira.

i) Região da Vila São Vicente - Convenente e Parceiro Executor Prefeitura Municipal de Buritis ADSVRU

O APL de Apicultura do entorno do DF não faz parte da Rota do Mel e não é considerado APL de integração, entretanto, parte do APL do Mel é reconhecido no Estado de Goiás.

Somente uma parte desses APLs são articulados com Brasília. Aguarda-se ainda a atuação do Decreto n. 34.765, de 25 de outubro de 2013, que institui o Núcleo de Apoio aos Arranjos Produtivos Locais do Distrito Federal. Perante o artigo $3^{\circ}$, a Universidade de Brasília foi convidada para participar do núcleo. Contudo, o NIT-UNB deveria participar da definição e da gestão do núcleo.

Na lista dos APLs estruturados do DF, atualizados para o ano 2018, há os seguintes:
a) APL de Agricultura Orgânica do DF.
b) APL de Flores e Plantas Ornamentais.
c) APL de Gemas e Joias.
d) APL das Empresas Gráficas do DF.
e) APL de Madeira e Móveis do DF.
f) APL de Resíduos Sólidos, Recicláveis e Reciclados.
g) APL de Suinocultura.
h) APL de Piscicultura.
i) APL da Avicultura.
j) APL de Tecnologia da Informação e Comunicação.
k) APL de Turismo.
1) APL de Vestuário. 
Todavia, não todos os APLs da RIDE e do DF podem ser alvos de pedido de IG. Os produtos mais conhecidos são produtos derivados de tradições de lavoura permanente e em todas as produções agropecuárias. A atual pesquisa limitou-se à análise dos APLs das produções agrícolas ou agropecuárias e de pedras e gemas (atividade de mineração ou extrativa e artesanal) mais relacionados aos IG existentes atualmente na região Centro-Oeste, a saber: APL de Gemas e Joias do DF e Cristalina/GO, APL de Artesanato Mineral, APL de Apicultura da RIDE, APL de Agricultura Orgânica do DF.

Isso por duas motivações: a necessidade de reduzir o universo de pesquisa em uma amostra e, secundariamente, devido à falta de dados quantitativos encontrados, o que inviabiliza esse tipo de pesquisa aprofundada. Para uma pesquisa sistemática com dados quantitativos, é preciso haver disponibilidade de fundos de custeio e pesquisadores. Uma via é de completar a análise iniciada no atual trabalho com a contribuição de pesquisa em cursos de propriedade intelectual ou agronegócio.

Como já relatado, a pesquisa quantitativa dos APLs escolhidos é pouco significativa, visto que as agências gestoras dos programas, pelo menos nos dados abertos encontrados, não fornecem dados significativos. Faltam, sobretudo, informações sobre vendas e cotas de mercado dos produtores por Município, que torna impossível usar indicadores mais sofisticados que o QL.

Por causa das dificuldades encontradas, escolheu-se desenvolver os seguintes passos na análise: a) análise das informações de base obtidas de APL (vários: IPEA, Sebrae e MI); e b) relacionamento com base dados IBGE (Sidra) para análise da concentração. Os resultados são explicados nas sucessivas seções. Os dados quantitativos então foram obtidos na base de dados do censo agropecuário do IBGE (Sidra) e Ministério Minas e Energia. Na análise, então, devido ao tipo de informação encontrada, foram escolhidos finalmente os seguintes produtos:

a) Mel: APL RIDE de apicultura;

b) Morango: APL agricultura Orgânica DF; e

c) Gemas e Joias: APL de Gemas e Joias DF.

Os dados quantitativos encontrados permitiram calcular o QL somente para apicultura e produção de morango. Não foi possível analisar o QL da produção de pedras e joias ligada a uma cadeia de extração, produção e venda nas lojas, mas somente o fato de existirem dados das associações que indicam concentração já tem importância relativa dos polos de Brasília e de Cristalina.

Vale ressaltar que os cálculos na seção sucessiva são limitados também em: a) estimativas (2017) do censo agropecuário do IBGE cuja última análise foi em 2006; e b) variância do QL na comparação com dados de todo o Brasil. Essa crítica se encontra na análise de Crocco et al. (2003). 
Tabela 1 - Censo agropecuário 2017 - pessoal ocupado e estabelecimentos

\begin{tabular}{|c|c|c|c|c|c|}
\hline & pessoal ocupado & $\%$ & estabelecimentos & $\%$ & $\begin{array}{c}\text { média } \\
\text { ocupados }\end{array}$ \\
\hline BRASIL & 15.036 .978 & 1 & 5.072 .152 & $100,0 \%$ & 3,0 \\
\hline $\mathrm{DF}$ & 21.812 & $0,1 \%$ & 5.246 & $0,1 \%$ & 4,2 \\
\hline GOIÁS & 486.005 & $3,2 \%$ & 152.089 & $3,0 \%$ & 3,2 \\
\hline MINAS GERAIS & 1.825 .141 & $12,1 \%$ & 607.448 & $12,0 \%$ & 3,0 \\
\hline Entorno do DF (33 municipios) & 113.647 & $0,8 \%$ & 34.073 & $0,7 \%$ & 3,3 \\
\hline $\mathrm{DF}$ & $21.812^{\prime}$ & $0,1 \%$ & 5.246 & $0,1 \%$ & 4,2 \\
\hline Total RIDE-DF & $135.459^{\prime}$ & $0,9 \%$ & 39.319 & $0,8 \%$ & 3,4 \\
\hline
\end{tabular}

Fonte: Elaborada pelo autor deste artigo com base no site IBGE (2019)

Minas Gerais é o Estado, entre Goiás e DF, cuja população agrícola é relativamente a mais numerosa, tem aproximadamente três vezes a média nacional de 578 mil unidades (total dividido por 26 estados), representada pelo estado de Goiás e DF juntos. A RIDE-DF concentra cerca de $1 \%$ do pessoal ocupado de todo o Brasil e 0,8\% dos estabelecimentos.

Com base nessas informações gerais e nos detalhes do município, é possível construir índices de localização considerando os números de pessoas ocupadas e de estabelecimentos relativo aos APLs, produtos de mel e do morango. A respeito do morango, é possível fazer uma análise da relação do total da horticultura e do morango para verificar a concentração do fruto relativa a toda indústria.

\subsection{Análise do Mel - APL RIDE de Apicultura}

Iniciando com o mel, os dados sobre a apicultura são mostrados a seguir, usando os dados do SIDRA (IBGE, 2019) estimativa de 2017. O mel é um dos produtos com estatísticas próprias, segundo os dados do IBGE (2019). O número de estabelecimentos na RIDE-DF é representado na tabela a seguir.

Tabela 2 - Número de estabelecimentos de mel (por Estado) na RIDE-DF

\begin{tabular}{crr}
\hline & estabelecimentos & $\%$ \\
\hline DF & 39 & $21,2 \%$ \\
\hline GOIÁS & 120 & $65,2 \%$ \\
\hline MINAS GERAIS & 25 & $13,6 \%$ \\
& & \\
\hline Total RIDE-DF & 184 & $100,0 \%$ \\
\hline
\end{tabular}

Fonte: Elaborada pelo autor deste artigo com base em IBGE (2019)

Analisando a concentração por município, percebe-se que a concentração dos estabelecimentos nos municípios da RIDE-DF mostra que quatro municípios de Goiás concentram 53\% dos estabelecimentos de todos os municípios de Goiás. 
Tabela 3 - Concentração empresas em Goiás

\begin{tabular}{lcr}
\hline Municípios & número & $\%$ cumulativo \\
\hline Formosa (GO) & 26 & $22 \%$ \\
\hline Luziânia (GO) & 14 & $33 \%$ \\
\hline São João d'Aliança (GC & 12 & $43 \%$ \\
\hline Padre Bernardo (GO) & 12 & $53 \%$ \\
\hline
\end{tabular}

Fonte: Elaborada pelo autor deste artigo com base em IBGE (2019)

Considerando toda a RIDE-DF, a situação muda, pois o DF e Buritis juntos acumulam 57\% do total dos estabelecimentos da RIDE-DF. Não se sabe em quais Regiões Administrativas no DF se concentram os estabelecimentos de mel.

Tabela 4 - Concentração na RIDE-DF

\begin{tabular}{lcr}
\hline Municípios & número & $\%$ cumulativo \\
\hline Brasília (DF) & 39 & $21 \%$ \\
\hline Formosa (GO) & 26 & $35 \%$ \\
\hline Buritis (MG) & 15 & $43 \%$ \\
\hline Luziânia (GO) & 14 & $51 \%$ \\
\hline
\end{tabular}

Fonte: Elaborada pelo autor deste artigo com base em IBGE (2019)

Sendo que Formosa (GO) e Buritis (MG) formam divisa com o DF. Uma análise nos municípios do Norte e do Leste em relação à concentração territorial mostra que há uma concentração maior dos apicultores ao redor de Formosa. Nesse arco, que vai de Padre Bernardo (GO) a Arinos (MG), considerando o DF também, concentra-se mais de $80 \%$ do total dos produtores da RIDE-DF.

Isso mostra também que as associações de apicultura ligadas aos estados provavelmente terão uma atitude conflituosa entre si, caso não tenham um controle em instância superior (União), pois não é interesse de cada Estado favorecer os outros. O DF, que tem a maioria relativa ( $21 \%$ no total de toda RIDE-DF) de estabelecimentos, também é o maior centro de consumo do mel no território, cuja produção não é suficiente para abastecer o mercado. Parte do consumo do DF é importado de fora. 
Tabela 5 - Total de estabelecimentos dos municípios da RIDE-DF no arco Norte/Nordeste

\begin{tabular}{lccc}
\hline ANÁLISE DOS MUNICíPIOS & número & total & $\%$ \\
\hline Brasília (DF) & 39 & 39 & \\
\hline Goiás (Arco norte-este): & & & \\
\hline Água Fria de Goiás (GO) & 4 & & \\
\hline Alto Paraíso de Goiás (GO) & 4 & & \\
\hline Alvorada do Norte (GO) & 1 & & \\
\hline Arinos (MG) & 10 & & \\
\hline Buritis (MG) & 15 & & \\
\hline Cabeceiras (GO) & 4 & & \\
\hline Cavalcante (GO) & 1 & & \\
\hline Flores de Goiás (GO) & 8 & & \\
\hline Formosa (GO) & 26 & & \\
\hline Mimoso de Goiás (GO) & 1 & & \\
\hline Niquelândia (GO) & 7 & & $19 \%$ \\
\hline Padre Bernardo (GO) & 12 & & \\
\hline Planaltina (GO) & 3 & & $100 \%$ \\
\hline São João d'Aliança (GO) & 12 & & \\
\hline Vila Boa (GO) & 2 & 110 & \\
\hline outros (MG e Goiás) & 35 & 35 & \\
\hline total & 184 & 184 & \\
\hline
\end{tabular}

Fonte: Elaborada pelo autor deste artigo com base em IBGE (2019)

Considerando o número de pessoas ocupadas na apicultura, os índices QL relativos ao DF e à RIDE se apresentam em concentração média e em alta concentração pela RIDE, observando que o total de empregos estimados relativos ao total de empregos na apicultura dos Estados de Goiás, Minas Gerais e do Distrito Federal alcança 14,41\% do total dos empregos na apicultura em relação ao Brasil. O QL relata uma situação superior a 1 , o que se traduz em alta concentração manifesta.

\begin{tabular}{|lrlll|}
\hline QL & 3,288 & Q $>1$ & \\
& RIDE DF & 12,685 & Q $>1$ & alta concentração \\
& & & \\
\hline
\end{tabular}

A alta concentração se revela observando também o número de empresas relacionadas ao total das empresas com a diferença de que o número de empresas no DF é significativamente mais baixo, o que implica menos concentração. Essa diferença com o QL relativo ao pessoal empregado é a de que o número de empregados no DF é maior, embora não signifique que, no DF, todo pessoal da empresa esteja concentrado na apicultura, mas pode ter produções diversificadas.

\begin{tabular}{|c|c|c|c|c|}
\hline \multirow[t]{2}{*}{$\mathrm{QL}$} & DF & 0,02 & $Q L>1$ & \\
\hline & RIDE & 10,27 & $Q L>1$ & alta concetração \\
\hline
\end{tabular}

Ao final, é evidente a alta concentração na RIDE-DF da apicultura, o que implica uma fatia de mercado que precisa de promoção e marketing com foco nesse produto. 


\subsection{Análise do Morango - APL Agricultura Orgânica DF}

Em relação à horticultura e ao morango, os dados SIDRA (IBGE, 2019) mostram a seguinte situação do produto no Brasil e na RIDE. Os municípios de Minas Gerais e do entorno não produzem morango, por isso, na RIDE-DF, não há municípios de MG em relação ao morango.

A horticultura pode ser orgânica ou não orgânica, no caso do APL de agricultura orgânica, não se tem uma divisão entre agricultura e horticultura. Os dados do IBGE (2019), de outro lado, não permitem essa separação, também não se há dados da Codeplan (agência que cuida de estatísticas do DF) sobre esse assunto.

Tabela 6 - Número de estabelecimentos da horticultura - morango

\begin{tabular}{lrcc}
\hline & estabelecimentos & $\%$ & $\begin{array}{c}\% \\
\text { cumulativo }\end{array}$ \\
\hline Brasil & 12.994 & $100 \%$ & \\
\hline Brasilia (DF) & 329 & $3 \%$ & \\
\hline Goiás & 222 & $2 \%$ & \\
\hline total Brasilia e Goiás & 551 & $4 \%$ & \\
\hline Águas Lindas de Goiás (GO) & 2 & $0 \%$ & $0,9 \%$ \\
\hline Alto Paraiso de Goiás (GO) & 2 & $0 \%$ & $0,9 \%$ \\
\hline Cabeceiras (GO) & 1 & $0 \%$ & $0,5 \%$ \\
\hline Cristalina (GO) & 2 & $0 \%$ & $0,9 \%$ \\
\hline Formosa (GO) & 5 & $0 \%$ & $2,3 \%$ \\
\hline Luziânia (GO) & 2 & $0 \%$ & $0,9 \%$ \\
\hline Padre Bernardo (GO) & 16 & $0 \%$ & $7,2 \%$ \\
\hline Planaltina (GO) & 2 & $0 \%$ & $0,9 \%$ \\
\hline Total GO & 32 & $0 \%$ & $14,4 \%$ \\
\hline & & & $1,7 \%$ \\
Brasilia (DF) & 329 & $3 \%$ & $16,1 \%$ \\
TOTAL & 361 & $3 \%$ & \\
\hline
\end{tabular}

Fonte: Elaborada pelo autor deste artigo com base em IBGE (2019)

Em relação à horticultura, o QL mostra uma concentração muito baixa na RIDE de empregos regionais.

\begin{tabular}{|llll|}
\hline QL & DF & 0,329 & QL $<1$ \\
& RIDE & 0,528 & QL $<1$ \\
\hline
\end{tabular}

O mesmo valor é encontrado quando se analisa o número de empresas.

\begin{tabular}{|llll|}
\hline QL & & & \\
& DF & 0,045 & $\mathrm{QL}<1$ \\
& RIDE & 0,081 & $\mathrm{QL}<1$ \\
\hline
\end{tabular}


Porém, em relação ao morango, o QL mostra uma concentração alta na RIDE de empregos regionais.

\begin{tabular}{|llll|}
\hline QL & & & \\
& DF & 3,034 & QL>1 \\
& RIDE & 3,261 & QL>1 \\
\hline
\end{tabular}

O QL também é alto quando se analisa o número de empresas. A concentração é alta devido ao número relativamente alto de empresas presentes, sobretudo, no DF.

\begin{tabular}{|llrl|}
\hline QL & & & \\
& DF & 9,883 & QL>1 \\
& RIDE & 10,845 & QL>1 \\
\hline
\end{tabular}

A concentração acontece no DF, em particular na Região Administrativa de Brazilândia que foi alvo da análise de campo exploratória. Considerando que Padre Bernardo e Águas Lindas de Goiás fazem divisa com o DF, tem-se $96,1 \%$ da produção de morango concentrada nesse território.

Conclui-se que o morango é efetivamente um produto típico do DF com alta concentração de empresas e de emprego, fato que poderia tornar o DF a primeira IG do estado.

\subsection{Gemas e Joias - APL de Gemas e Joias DF e Cristalina/GO}

Em relação aos dados quantitativos sobre APL de Joias, não foi possível calcular indicadores de concentração e quociente locacional QL. Alguma informação vem da pesquisa de campo e outra do relatório de APL predisposto em 2007. A síntese é a seguinte.

Tabela 10 - Número de empresas do APL do DF

\begin{tabular}{lcr}
\hline ATIVIDADE & EMPRESA & \multicolumn{1}{c}{$\%$} \\
\hline Jóias & 68 & 45,9 \\
Folhados e bijuterias & 44 & 29,7 \\
Artesanato em geral & 8 & 5,4 \\
Gemas naturais & 7 & 4,7 \\
Artesanato mineral & 2 & 1,4 \\
Outras gemas simulantes & 1 & 0,7 \\
Obras de arte & 1 & 0,7 \\
Outros & 17 & 10.9 \\
\hline TOTAL & 148 \\
\hline
\end{tabular}

Fonte: Elaborada pelo autor deste artigo com base em Leite (2007, p. 14)

Recentes pesquisas realizadas pelo Serviço de Apoio às Micro e Pequenas Empresas do Distrito Federal identificaram cerca de 150 empresas dos segmentos de Gemas, Joias, Bijuterias e Correlatos, com o intuito de conhecer aspectos relativos à identificação e ao perfil da empresa e do empresário, produção de equipamentos, comercialização, organização e administração e recursos humanos. Os mais de 120 empresários e artesãos da região - metade deles está asso- 
ciada à Associação dos Produtores de Pedra de Cristalina (ASPEC) - direcionaram suas linhas para produtos utilitários, como artefatos minerais, tabuleiros de xadrez, bandejas, etc.

Como síntese final desta seção, pode-se afirmar que há, efetivamente, sobretudo nos APL de mel e morango, e com alguma reserva também de joias, condições relativas que podem justificar uma IG, seja por indicação de procedência ou por denominação de origem.

\section{Discussão}

O resultado da análise quantitativa, aproveitando-se das informações sobre APLs e dados disponíveis do IBGE e da CODEPLAN no DF, pode ser usado para sugerir políticas públicas. Uma análise de concentração em termos de estabelecimentos e de número de pessoas empregadas deveria ser acompanhada também do faturamento e das áreas aproveitadas pelas culturas, no caso do morango, e relacionada a vendas para mel e joias. Um conjunto de dados quantitativos, que possam mapear concentrações de produtividade, é fundamental para apoiar tomadas de decisões de investimentos. Esses dados também podem ser usados para incentivos e políticas de fomento.

Em particular, os dados quantitativos permitem inferir quanto será o provável resultado de investimentos e de políticas públicas, ou seja, para avaliação delas. Isso é um dos pontos mais fracos em relação aos resultados das políticas públicas desenvolvidas. Os impactos e o desenvolvimento não são sempre o resultado dos objetivos iniciais. A metodologia de análise sugerida, a ligação com APL, deveria facilitar essa busca de resultados quantitativos, pois os APL são parte de uma agenda consolidada de políticas econômicas de desenvolvimento e de integração regional no Brasil.

Outro ponto importante, derivado dos resultados, é que os indicadores de localização revelam que o possível território de obtenção da IG ultrapassa a unidade federativa. Em particular o mel, mas também morango e joias mostram que, na realidade, os produtos e as cadeias produtivas perpassam a unidade federativa, seja município ou estado. Não por acaso, o Ministério da Integração, trabalhando com APL, organiza os APLs nacionais em "rotas" ou arranjos. Assim se encontram na classificação, por exemplo: Rotas do Mel e do Turismo. Esse aspecto está sendo percebido não apenas para APL, mas para todas as cadeias e, sobretudo, nas "Supply Chain" de commodities.

A possibilidade de encontrar concentrações de produtores que trabalham em áreas produtivas inter e infra às unidades territoriais é muito alta, como é mostrado na análise da RIDE-DF. Em relação à IG, isso cria problemas de articulação territorial entre município e municípios e estados que somente podem ser superados com acordos e conferências que geram contratos territoriais para aproveitamento dos recursos produtivos e desenvolvimento. Esses acordos podem ser desenvolvidos somente com instrumentos legais predefinidos e fomentados pela União e devem ser obrigatoriamente cumpridos pelos Estados. A alternativa de construir acordos interestaduais somente depois é ineficiente e dificilmente realizável sem um poder superior, dependendo da boa vontade dos governadores.

Para superar este último gargalo, a solução é desenvolver acordos entre associações de produtores por meio de outras certificações e marcas, como as marcas coletivas. Esse parece 
ser o movimento atual de alguma associação, como a dos artesãos e dos produtores de vinho. Porém, uma solução desse tipo esvazia a significatividade da Indicação Geográfica.

Outra alternativa poderia ser autorizar o Ministério da Agricultura, Pecuária e Abastecimento, que em outros países é o ator mais importante nas decisões sobre IG, a superar indicações e documentação necessariamente produzidas pelos municípios e estados, com uma análise formal e de mérito relativa à certificação, tirando essa exigência da regulamentação atual.

Enfim, uma alternativa poderia ser autorizar IGs Estaduais, com o mesmo nome, mas indicado pelo Estado, e definir uma marca nacional única de IG que possa mostrar a conexão entre diversas IGs, como existe na Europa.

\section{Considerações Finais}

Em relação aos objetivos iniciais, pode-se notar que a pesquisa trouxe vários desafios em relação à formação de uma base de dados confiáveis e de informações. Teoricamente, os procedimentos metodológicos que implicam as informações sobre APL e o censo agropecuário têm um amparo científico correto. Porém, as dificuldades em encontrar informações confiáveis e continuativas significam que há sempre um viés na análise quantitativa. Além disso, faltam dados sobre faturamento para analise de concentração concorrencial no mercado.

Uma sugestão para superar o problema de base de dados quantitativos e de faturamento é procurar informações diretamente nas associações de produtores. Um elemento fundamental de pesquisa para avaliação comercial é trabalhar com informações sobre faturamento: quantidades, preços e dados de mercado (por exemplo: concorrentes).

Com base nesta primeira pesquisa quantitativa no DF, a primeira com este método, percebe-se que há indicações de produtos com potencial suficiente para requerer certificação de IG e isso pode ser avaliado diretamente pelo censo agropecuário do IBGE e pelas informações sobre APL presentes. Assim, a pesquisa valida a metodologia do uso dos APLs e dos índices de concentração para triagem dos potenciais para IG na Região Metropolitana de Brasília.

Enfim, a análise quantitativa levanta também muitas questões de como usar e avaliar os resultados. Os mais importantes questionamentos são relativos ao possível uso dessas informações para políticas econômicas locais e seus impactos no PIB regional. Também o problema de avaliar as cadeias produtivas e as dificuldades do pedido de IG de produtos que se encontram simultaneamente em diferentes municípios e estados permanece não solucionado. Nos dois casos, a sugestão é o diálogo institucional, mas a disponibilidade de um observatório com dados quantitativos poderia ser útil na discussão se ele fosse implementado, pois, pelo menos, seria mais claro e teria uma base técnico cientifica sobre a qual tomar decisões políticas. Isso poderia ser o papel do NIT da UNB de onde saiu esta pesquisa.

\section{Referências}

BASILE, E.; CECCHI C. La trasformazione post-industriale della campagna: dall'agricoltura ai sistemi locali rurali. Torino: Rosenberg \& Sellier, 2001.

BASILE, E.; CECCHI, C. Building Social Capital in Rural Areas: Does Public Action Help? First International Conference on Engaging Communities, Brisbane, Agosto, 2005. 
BRASIL. Decreto n. 1.355, de 30 de dezembro de 1994. Promulgo a Ata Final que Incorpora os Resultados da Rodada Uruguai de Negociações Comerciais Multilaterais do GATT, 1994.

BRASIL. Lei n. 9.279, de 14 de maio de 1996. Regula direitos e obrigações relativos à Propriedade Industrial. Brasília: Congresso Nacional, 1996.

BRITTO, J.; ALBUQUERQUE, E. M. Clusters industriais na economia brasileira: uma análise exploratória a partir de dados da RAIS. Estudos Econômicos, São Paulo, v. 32, n. 1, p. 71-102, 2002.

BRITTO, J.; ALBUQUERQUE, E. M. Estrutura e dinamismo de clusters industriais na economia brasileira: uma análise exploratória a partir dos dados da RAIS. In: TIRONI, L. F. Industrialização descentralizada: sistemas industriais locais. Brasília: IPEA, 2001. Cap. 1.

CASSIOLATO H. M. M.; J.; ARROIO, A. Conhecimento, sistemas de inovação e desenvolvimento. Rio de Janeiro: UFRJ/Contraponto, 2005.

CROCCO, M. A. et al. Metodologia de Identificação de Arranjos Produtivos Locais Potenciais: uma Nota Técnica. Belo Horizonte: UFMG/CEDEPLAR, 2003. (Texto para Discussão, 191). Disponível em: http://www.cedeplar.ufmg.br/pesquisas/td.html. Acesso em: 27 maio 2018.

GOIÁS. (Estado). Secretaria de Estado da Administração. 2020. Disponível em: SIGplan-GO: www.sigplan.go.gov.br. Acesso em: 20 mar. 2020.

IBGE - INSTITUTO BRASILEIRO DE GEOGRAFIA E ESTATISTICAS. SIDRA: Banco de tabelas estatísticas. 2019. Disponível em: Sidra-IBGE. www.sidra.gov.br. Acesso em: 20 mar. 2020.

INPI - INSTITUTO NACIONAL DA PROPRIEDADE INDUSTRIAL. Instrução Normativa n. 25, de 21 de agosto de 2013. Estabelece as condições para o Registro das Indicações Geográficas. Disponível em: http://www.inpi.gov.br/legislacao-1/in_25_21_de_agosto_de_2013.pdf. Acesso em: 27 maio 2018

IPEA - INSTITUTO DE PESQUISA ECONÔMICA APLICADA. Arranjos produtivos locais e desenvolvimento. Organizadores: Carlos Wagner de A. Oliveira, José Augusto V. Costa, Gabriela Maretto Figueiredo, Alessandra Ribeiro de Moraes, Ricardo Batista Carneiro, Iedo Brito da Silva. Rio de Janeiro: Ipea, 2017. 304. p.

LEITE, Rogério. Viana Plano de desenvolvimento preliminar (PDP) do APL de gemas e Jóias do Distrito Federal. [S.l.: s.n.], 2007.

MARSHALL, A. Principles of economics. Londres: MacMillan, 1920.

OECD - Organisation for Economic Co-operation and Development. Working Party on

Agricultural Policies and Markets of the Committee for Agriculture: Joint Working Party of the Committee for Agriculture and the Trade Committee. Paris. 21, Dec. 2000.

SEBRAE. Subsídios para a Identificação de Clusters no Brasil. Dezembro de 2002.

SEBRAE-MG/IEL. Aglomerações Produtivas em Minas Gerais e Belo Horizonte: identificação e mapeamento. Abril de 2003.

SISTEMA FIESP. Manual de Atuação em Arranjos Produtivos Locais - APLs. Brasília, DF, Governo Federal, 2014.

SUZIGAN, W. et al. Coeficientes de Gini locacionais - GL: aplicação à indústria de calçados do Estado de São Paulo. Nova Economia, Belo Horizonte, v. 13, n. 2, p. 39-60, julho-dezembro de 2003. 
UFRJ - UNIVERSIDADE FEDERAL DE RIO DE JANEIRO. Rotas de Integração Nacional: Sumário executivo. Rio de Janeiro: Instituto de Economia Marcelo Matos, Ana Lucia Tatsch, Francisco de Assis Costa, Marisa Botelho, Paulo Cavalcanti Filho, Sergio Castro, 2015.

\title{
Sobre o Autor
}

\author{
Alessandro Aveni \\ E-mail: alessandro@unb.br \\ Doutorado em Administração. \\ Endereço profissional: Universidade de Brasília, CDT, Campus Darcy Riberio, Asa Norte, Brasília, DF. CEP: \\ 70904-970.
}

